\title{
Microstructural Characterization of a Thermal Barrier Coating System Using SEM, TEM and APT Techniques
}

\author{
Y. Chen ${ }^{1}$, R. C. Reed ${ }^{2}$ and E. A. Marquis ${ }^{1}$ \\ 1. Department of Materials Science and Engineering, University of Michigan, Ann Arbor, Michigan \\ 48109-2136, USA \\ 2. Department of Engineering Science, University of Oxford, Parks Road, Oxford, OX1 3PJ, UK
}

Thermal barrier coatings (TBCs) are essential in protecting hottest components of jet engines during severe operating conditions [1]. To be functional, TBC systems must meet numerous requirements which include low thermal conductivity, high resistivity to oxidation and corrosion depending on operating conditions, equal or similar thermal expansion coefficients with the substrate and substantial toughness. There is no single material that can meet all of these specifications; therefore TBCs consist of layers of different materials. In general TBCs have a ceramic top coat to provide the thermal barrier to lower the effective temperature on substrate. A compositional modified bond coat underneath is used to prevent oxidation of the substrate and to promote better adhesion between the metal and the ceramic. In addition, the microstructure of TBCs can become even more complex during service due to the formation of a so-called thermally-grown oxide (TGO) layer at ceramic/bond coat interface that grows from $<100 \mathrm{~nm}$ to up to $10 \mu \mathrm{m}$. Many studies have indicated that failure of TBCs generally occurs at the TGO layer [2], and mechanical origins have been well addressed previously.

The aim of this work is to consider the possible chemical origins of TBC failure, in particular interfacial segregation. The microscopy challenge resides in the need for high spatial and chemical sensitivity to characterize a microstructure involving multiple length scales, chemical and topological inhomogeneities and complexities. Only then can the evolution of the TBC structure be described and understood in term of transport kinetics and thermodynamic stability.

The analysed TBC structure was prepared on a real turbine blade fabricated from a CMSX-4 single crystal superalloy with composition shown in Table 1 [3]. Cross-sectional microstructural image of TBC in as-coated condition taken by scanning electron microscopy is shown in Figure 1(a) showing the $100 \mu \mathrm{m}$ thick yttria-stabilized zirconia (YSZ) coating deposited on a Pt-diffused bond coat on top of the superalloy. The thin TGO layer formed along the interface of ceramic/bond coat interface has a wavy structure. A more detailed microstructural characterization of TGO was carried out using transmission electron microscopy (TEM) with specimens prepared by focused ion beam milling. Such image in Figure 1(b) shows the three expected layers: YSZ top coat with a columnar grain and some porosity, a thin TGO layer of thickness varying from $100 \mathrm{~nm}$ to $1 \mathrm{um}$, and the underlying Pt-diffused layer. The TGO layer has a duplex structure consisting of alternating regions of $\mathrm{ZrO}_{2}-\mathrm{Al}_{2} \mathrm{O}_{3}$ mixed oxide and coarse $\alpha-\mathrm{Al}_{2} \mathrm{O}_{3}$ grains determined by electron diffraction. The bond coat consists primarily of $\gamma^{\prime}$ grains of size $\sim 1 \mu \mathrm{m}$. Some $\gamma$ regions are also present but only at the interface; those are identified using EDX analysis by their higher concentration in $\mathrm{Cr}$, Co and lower in Al. Due to the complexity in chemistry and microstructure, interfacial chemistry in the different regions is probed by atom probe tomography (APT). One of such regions is the TGO/bond coat interface at where cracking is prone to start. Figure 2 (a) and (b) show APT reconstruction from $\mathrm{TGO} / \gamma$ and $\mathrm{TGO} / \gamma^{\prime}$ interfaces, respectively. Pt segregation at the $\mathrm{TGO} / \gamma$ but no Pt enrichment at the $\mathrm{TGO} / \gamma^{\prime}$ interface are observed. Minor alloying additions (Hf, $\mathrm{Zr}, \mathrm{Si}$ ) either originating from the alloy or from the YSZ coating are found along grain boundaries in the 
TGO (Figure 2(c)), suggesting complex mass transport across the various interfaces. The evolution of the structure from the as-processed state to after treatments at high temperature and consequences of elemental segregation and concentration gradients at and near interfaces will be discussed.

\section{References:}

[1] Evans AG, et.al. Prog Mater Sci 46 (2001), p505-553

[2] R.T. Wu, R.C. Reed, Acta Materialia 56 (2008), p313-323

[3] Y. Chen, R.C. Reed, E.A.Marquis, Scripta Materialia 67 (2012), p779-782

[4] The authors acknowledge financial support from the College of Engineering at the University of Michigan.

Table 1. Nominal chemical compositions (at.\%) of the superalloy substrate.

\begin{tabular}{|c|c|c|c|c|c|c|c|c|c|c|}
\hline Element & Co & $\mathrm{Cr}$ & Mo & W & Al & $\mathrm{Ti}$ & $\mathrm{Ta}$ & $\mathrm{Hf}$ & $\mathrm{Re}$ & $\mathrm{Ni}$ \\
\hline CMSX-4 & 9.91 & 7.6 & 0.38 & 2.12 & 12.62 & 1.27 & 2.18 & 0.03 & 0.98 & 62.91 \\
\hline
\end{tabular}
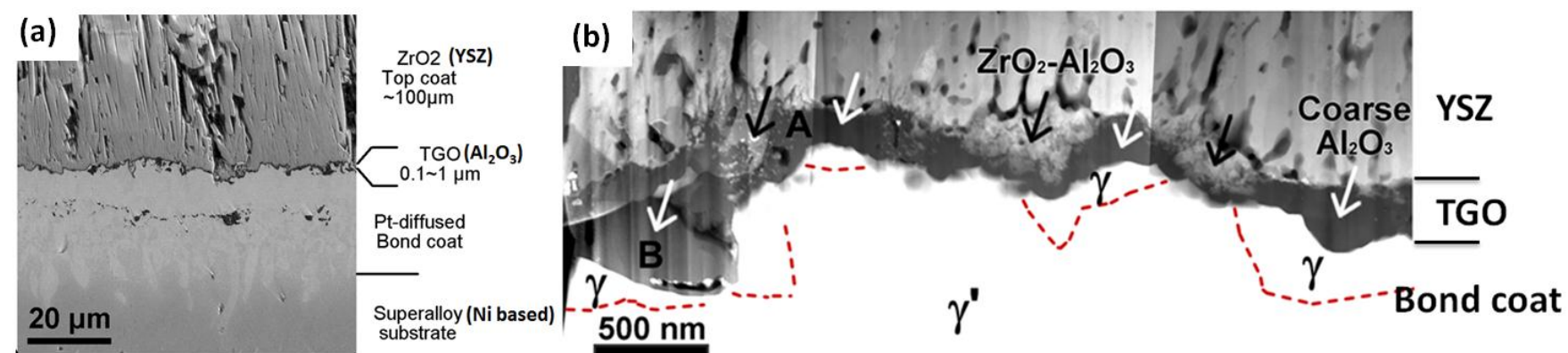

Figure 1. (a) is cross-sectional SEM image of the TBC structure. (b) is cross-sectional STEM image of the TBC structure in the as-processed condition in where dashed lines highlight locations of the $\gamma$ in the bond coat as determined by EDX and electron diffraction analysis.

(a)

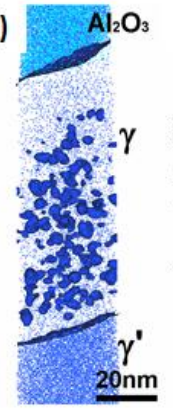

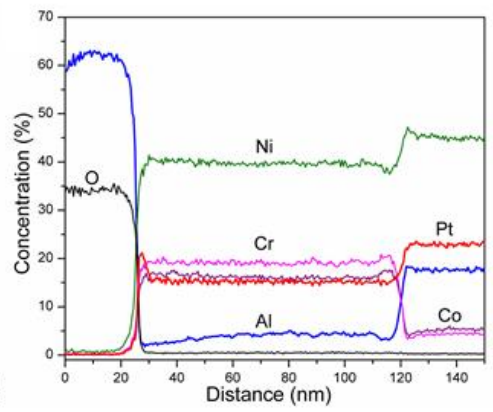
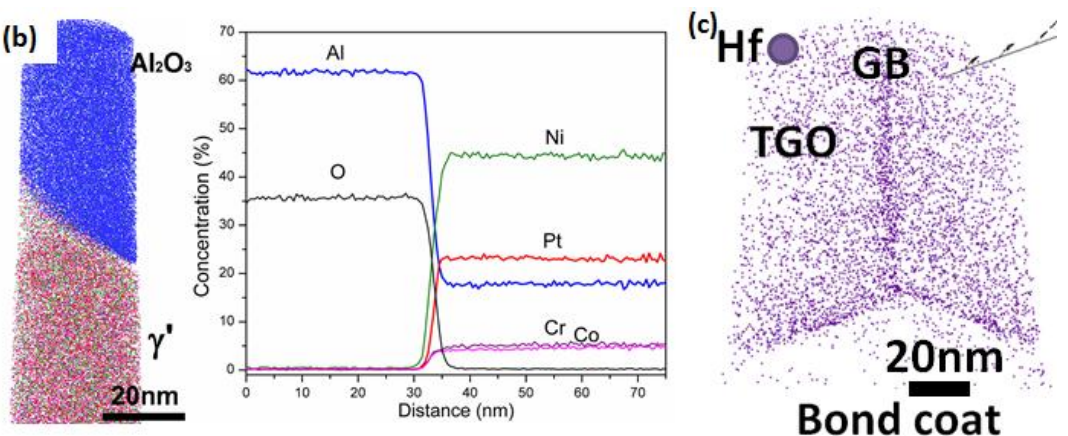

Figure 2. Three-dimensional APT reconstruction of (a) $\mathrm{TGO} / \gamma / \gamma^{\prime}$ and (b)TGO/ $\gamma^{\prime}$ interfaces in the asprocessed condition. Concentration profiles taken perpendicular to the interfaces are shown beside. (c) is evidence of Hf segregation on grain boundary in TGO and on TGO/bond coat interface for annealed condition. 